\title{
RELAÇÕES DE PODER COMO GOVERNO NO ESPAÇO ESCOLAR
}

\section{ARTIGO ORIGINAL}

ANJOS, Silvana Reis dos ${ }^{1}$

FONTE, Sandra Soares Della ${ }^{2}$

ANJOS, Silvana Reis dos. FONTE, Sandra Soares Della. Relações de poder como governo no espaço escolar. Revista Científica Multidisciplinar Núcleo do Conhecimento. Ano 05, Ed. 05, Vol. 02, pp. 167-181. Maio de 2020. ISSN: 2448-0959, Link de acesso: https://www.nucleodoconhecimento.com.br/educacao/espaco$\underline{\text { escolar }}$

\section{RESUMO}

Este artigo tem como objetivo discutir as formas que as relações de poder assumem no espaço escolar, por meio da realização de um inventário das relações de poder em uma escola de ensino fundamental do município de Serra (ES), a partir do aporte metodológico do estudo de caso etnográfico. Para tanto, recorreu-se aos estudos de Michel Foucault que tratam da noção de poder como governo ou conduta. Ao focar as relações por esse viés, percebeu-se o exercício cotidiano da dominação, mas também se evidenciaram condutas que apontam para a ampliação do exercício da liberdade.

Palavras-Chave: Relações de poder, escola, liberdade.

\section{INTRODUÇÃO}

A compreensão do espaço escolar como lócus de dominação no qual os indivíduos estariam submetidos a formas coercitivas de poder constituiu uma tendência nas pesquisas educacionais hodiernas. Essa tendência é fruto das análises de Foucault

\footnotetext{
${ }^{1}$ Mestre em Educação Física.

${ }^{2}$ Doutora em Educação.
} 
sobre os mecanismos de poder disciplinar (FOUCAULT, 2007) e biopolítica (FOUCAULT, 1994) nas sociedades modernas, que, segundo Veiga-Neto (2011), têm sido a principal referência para o campo da pesquisa em educação.

A apropriação das análises dos mecanismos de poder disciplinar no campo das pesquisas educacionais convergiu para o reconhecimento, no espaço escolar, de relações de dominação, com o predomínio de formas coercitivas de poder sobre as ações dos indivíduos. Nesse sentido, uma série de trabalhos foi produzida evidenciando os mecanismos de poder operantes nesse espaço.[3]

A escola, nessa perspectiva, foi compreendida como uma instituição que retirava os corpos dos sujeitos do meio social mais amplo e os enclausuravam para incutir comportamentos convergentes a um indivíduo necessário à sociedade moderna que se constituía. O espaço escolar promovia a disciplinarização dos corpos, no sentido de torná-los dóceis, e assim, produtivos[4]. No entanto, a compreensão é parcial e relaciona-se a apenas uma faceta dos estudos de Foucault.

Acreditamos que essa compreensão não consiga abarcar a complexidade das relações produzidas no espaço escolar. Admitimos, com o aprofundamento da obra de Foucault, a liberdade como condição das relações de poder, e, por esse motivo, não podemos conceber a escola como lócus de controle total. Apesar de reconhecermos a existência de práticas de disciplinamento, pressupomos que a escola também seja lócus de resistência, uma vez que, a partir das ações dos sujeitos, podem ser reconhecidas algumas indicações de uma ressignificação perante as tentativas de controle operantes nesse espaço.

Com tal indicação, realizamos uma pesquisa cuja proposta foi observar as tensões entre as relações de poder na escola. Interessava-nos saber como eram as formas pelas quais os sujeitos construíam seus modos de conduzir e serem conduzidos diante da complexidade de relações no contexto escolar. Desejávamos incitar uma discussão sobre as formas de condução que ampliavam ou reduziam a experiência dos sujeitos. Dessa forma, o ambiente escolar apresentou-se como lugar complexo e 
que encerrava conflitos: a mesma escola que disciplinava os corpos, abria possibilidades ao exercício da liberdade.

As tensões entre as relações de poder na escola foram refletidas a partir da percepção de governo como conduta, uma vez que a grade conceitual tecida a partir da noção cunhada por Foucault em seus estudos tardios, oferece um entendimento que não pretende fixar as relações como dominação, mas, assumindo o poder como "ação sobre ações", faz ressaltar a ação individual e a liberdade nas relações de poder.

Nosso objetivo, dessa forma, foi verificar os modos por meio dos quais os sujeitos constroem as relações de poder no ambiente escolar. Como buscam conduzir e serem conduzidos em um espaço complexo como o escolar? Acreditamos, ainda, que a qualidade dessas relações possa nos indicar elementos para a compreensão do projeto de formação vigente nesse espaço.

\section{METODOLOGIA}

Nossa investigação pautou-se em uma abordagem qualitativa, mais precisamente na aplicação da abordagem etnográfica ao estudo de um caso. Por meio dessa abordagem, é possível obter "[...] uma visão profunda e ao mesmo tempo ampla e integrada de uma unidade social complexa de múltiplas variáveis" (ANDRÉ, 2010, p. 59). Para caracterizar o estudo de caso, delimitamos uma escola no município de Serra (ES) que, segundo levantamento prévio feito junto aos professores de Educação Física da rede de ensino municipal, destaca-se em relação à disciplina e controle dos alunos. Com o auxílio etnográfico, enfatizamos a construção dos processos, a valorização do significado que as pessoas atribuem às suas experiências e o reconhecimento de que o pesquisador não ocupa um lugar de neutralidade diante do que pesquisa. Por essa razão, adotamos a técnica da observação participante de momentos como: entrada e saída da escola, recreios, aulas de Educação Física e, também, reuniões do corpo pedagógico para avaliar qual o lugar que as atitudes dos alunos ocupam no planejamento dos trabalhos da escola. A coleta de dados foi realizada em um período de três meses e meio. 
Tivemos como foco da observação as práticas de uma professora de Educação Física com uma turma do primeiro ano do ensino fundamental, e as práticas de uma professora regente de classe com uma turma de terceiro ano. Já nos momentos de entrada, recreio, a ênfase foi dada às ações dos alunos perante o grupo de coordenadoras.

\section{A NOÇÃO DE PODER COMO GOVERNO EM MICHEL FOUCAULT}

A ênfase na noção de governo representa um deslocamento presente nos últimos trabalhos de Foucault. Para compreender o que isso representa, lembramos que o filósofo francês não concebe o poder como substância, nem como repressão, mas como exercício, como uma relação produtiva. Para evidenciar esse aspecto relacional e produtivo, o autor passou a estudar os mecanismos e técnicas de poder com destaque para a disciplina que operava no corpo do indivíduo, e o biopoder que incidia no homem enquanto espécie.

Foucault observou o exercício do poder na base do funcionamento de instituições como a fábrica, o hospital, a caserna e a escola. Nessas instituições, desenvolveu-se uma anátomo-política investindo no corpo a partir do seu esquadrinhamento no tempo e no espaço a fim de extrair ao máximo suas forças úteis e torná-los dóceis, sob a coerção de recursos como a vigilância, a normalização e a punição.[5]

O tratamento incisivo dos mecanismos suscitou a crítica de que Foucault não teria conferido espaço para liberdade nas relações. Assim, com a pretensão de ressaltar a dimensão subjetiva da ação, o filósofo realiza o primeiro deslocamento em sua obra ao tratar da relação entre poder e resistência, enfatizando a sua indissociabilidade do poder.

Para Foucault, resistência e poder são inseparáveis, uma vez que o poder existe "[...] em função de uma multiplicidade de pontos de resistência" (FOUCAULT, 1994, p. 98). Por esse motivo, não há relações de poder sem resistência, sem possibilidade de inversão de papéis, de burla, fuga ou escape. As resistências, nesse entendimento, 
"[...] desempenham nas relações de poder, o papel de adversário, de alvo, de apoio, de pretexto para uma intervenção" (FOUCAULT, 1994, p. 98).

Essa visão antagônica entre poder e resistência[6] é aos poucos abandonada por Foucault, uma vez que, segundo Ortega (1999), cria um impasse ao sugerir a saída de um sujeito dócil para um indivíduo extremamente ativo da resistência. $O$ estudioso se dirige, então, à noção que viria a ser para ele, o modo próprio das relações de poder.

O modo de relação próprio ao poder não deveria, portanto, ser buscado do lado da violência, nem da luta, nem do lado do contrato e da aliança voluntária (que não podem ser mais que instrumentos), mas ao lado deste modo de ação singular-nem guerreiro, nem jurídico- que é o governo (FOUCAULT, 1995, p. 244).

Segundo Sennelart (2008), nessa inflexão, Foucault trataria da temática do governo sob duas formas: as práticas de governo político de modo mais específico que se referia às estruturas políticas de gestão dos Estados, e, o governo em um plano amplo e geral, tal como era entendido no século XVI, quando "[...] designava a maneira de dirigir a conduta dos indivíduos ou dos grupos: governo das crianças, das almas, das comunidades, das famílias, dos doentes" (FOUCAULT, 1995, p.244). Em consequência desses desdobramentos, o governo é entendido como "[...] o conjunto de modos de ação mais ou menos refletidos e calculados, porém todos destinados a agir sobre as possibilidades de ação dos indivíduos" (FOUCAULT, 1995, p. 244).

Nesse sentido, é necessário lembrar, juntamente com as ideias de Foucault, que não há uma ruptura entre os mecanismos de poder e as artes de governar. Nem a disciplina, nem o biopoder são abandonados. Na verdade, eles se inserem como formas de condução necessárias à governamentalidade[7] quando propõem a vida como objeto de intervenção do poder.

No intuito de evidenciar aquilo que há de mais específico na relação de poder, seja ela pedagógica, familiar ou em relação às estruturas institucionalizadas, Foucault 
(1995) introduz a noção de conduta como forma de captar essa especificidade. O governo sob a forma de conduta refere-se ao mesmo tempo "[...] à ação de conduzir os outros (segundo mecanismos de coerção mais ou menos estritos) e à maneira de se comportar num campo mais ou menos aberto de possibilidades" (FOUCAULT, 1995, p. 244).

A importância da introdução dos conceitos de governo/conduta para os estudos das relações de poder é o estabelecimento da liberdade como condição dessas relações, e, ainda, o reconhecimento das possibilidades de escolha dos sujeitos entre diversas ações. Na forma de governo ou conduta, há sempre essa possibilidade, caso contrário, estaríamos diante de estados de dominação, que são relações nas quais há mínimas chances de liberdade. Dessa forma,

Quando definimos o exercício do poder como um modo de ação sobre as ações dos outros, quando as caracterizamos pelo 'governo' dos homens, uns pelos outros - no sentido mais extenso da palavra, incluímos um elemento importante: a liberdade (FOUCAULT, 1995, p. 244).

E, por último, com a pretensão de priorizar a conduta individual, Foucault se desloca de o eixo do poder/governo para o eixo ser-consigo. Nesses termos, o estudioso faz emergir o problema da vontade individual como possibilidade de recusa a determinadas formas de condução, ao explorar uma noção, em seus estudos sobre a Grécia Clássica: o cuidado si, que se refere a um processo por meio do qual o indivíduo experimenta técnicas sobre si,[8] a fim de se transformar e atingir um modo de ser. E isso, é claro, não poderia ser feito sob a égide da coerção, mas a partir de regras que o próprio indivíduo escolheria para conduzir-se.

O exercício do cuidado de si, dessa forma, refletia todo um trabalho do indivíduo sobre si próprio no intuito de constituir-se como sujeito moral dotado de um belo êthos, e, assim, poder exercer seu papel na cidade, ou seja, ocupar "[...] o lugar conveniente seja para exercer uma magistratura ou para manter relações de amizade" (FOUCAULT, 2004, p. 271). Ou melhor, "O princípio do cuidado de si versa que aquele 
que cuidasse adequadamente de si mesmo, era, por isso mesmo, capaz de se conduzir adequadamente em relação aos outros e para os outros" (FOUCAULT, 2004, p. 2).

A constituição de espaços de liberdade com o combate aos excessos de poder nas relações aparece, a partir de então, como preocupação fundamental nas análises de Foucault que destaca uma ética da conduta individual, com o estabelecimento de um governo de si, como forma de limitar as práticas abusivas de governo. Para Foucault (2004), a constituição de um governo de si como forma refletida da liberdade, pode desencadear uma atitude crítica que limitaria o governo de uns sobre os outros, partindo-se do pressuposto de que é preciso governar-se bem para assim, governar o outro.

A atitude crítica, para Foucault (1978), remete ao ato de questionar, diante de uma dada forma de governo, os efeitos de poder a partir dos quais os indivíduos seriam conduzidos. Partindo-se da reflexão da própria realidade, dos jogos de verdade e poder, é por meio dessa atitude crítica que os indivíduos podem romper com o assujeitamento, no momento em que questionam as formas de governo sob as quais estão submetidos e as formas pelas quais desejam ser governados. Assim, "[...] a crítica será a arte da inservidão voluntária, aquela da indocilidade refletida. A crítica teria essencialmente por função o desassujeitamento no jogo do que se poderia chamar, em uma palavra, a política da verdade" (FOUCAULT, 1978, p. 6).

Diante do exposto, destacamos a necessidade de discutir as práticas de condução dos sujeitos no espaço escolar, pois, conforme nos diz Foucault (1995), somente no exercício da relação é que podemos afirmar se estamos diante da liberdade ou da coerção. É preciso ressaltar também que o fato de se considerar a conduta como algo flexível não significa que não deva haver nenhuma espécie de condução na sociedade, e que todo poder é danoso. Para Foucault (2004, p. 284), não há problema nenhum "[...] na prática de alguém que, em um dado jogo de verdade, sabendo mais que o outro the diz o que é preciso fazer, ensina-lhe, transmite-lhe um saber, comunica-Ihe técnicas", o problema, nesse sentido, é a maneira pela qual as relações de poder são realizadas, ou mesmo, a necessidade de limitar os excessos de poder 
que "[...] farão com que um garoto seja submetido à autoridade arbitrária e inútil de um professor primário; um estudante, à tutela de um professor autoritário etc." (FOUCAULT, 2004, p. 284-285).

\section{RESULTADOS E DISCUSSÃO}

Lembrando que a conduta é, segundo Foucault (1978), uma forma de relação de poder na qual um indivíduo tenta dirigir a conduta do outro, vimos a escola abrir-se como um espaço complexo de condutas diversas, espaço de ambiguidades com ações e reações diversas com intensidades e impactos diferenciados.

Os dados que encontramos na EMEF Ordem e Progresso[9] sinalizaram dois grandes horizontes. Um deles compõe-se de condutas que se constroem a partir de contextos de dominação, nas quais há um cerceamento das escolhas dos indivíduos, e o outro, de condutas que sinalizam o exercício da liberdade com ampliação das possibilidades de ação dos sujeitos.

Em relação às condutas operadas pelo viés da dominação, encontramos elementos que indicam a busca pelo controle mediante a redução das escolhas dos sujeitos e, por isso, de seus espaços de liberdade. Essa redução foi visualizada já na entrada da escola, a partir da imposição de uma prática religiosa oficial, com orações e cantos, exilando outras experiências. Essa conduta, naturalizada no espaço escolar, põe em questão a laicidade da escola e, com isso, o respeito à coexistência das diversas manifestações culturais.

Nas aulas de Educação Física, encontramos uma forte pretensão em disciplinar os corpos. Observamos enorme esforço da professora para fixá-los em filas, em praticamente todas as atividades da aula, de forma que os alunos pudessem controlados.

A organização do espaço, nos esquemas disciplinares, é realizada de maneira a conferir visibilidade aos corpos e estabelecer um quadro 
classificatório e comparativo das individualidades [...]' (FOUCAULT, 2007, p. 126-127).

Não se trata de julgar a ação de estabelecer uma organização espacial, mas o fato de ser prioritariamente a forma única de condução dos alunos, exila outras formas criativas e reduz também as experiências espaciais dos sujeitos.

Em se tratando das práticas corporais conduzidas pela professora, a aula de Educação Física, aproxima-se da formação do corpo dócil, com a exigência da execução de gesto eficiente. A ginástica, realizada no início das aulas, exigia o silêncio e o gesto padronizado. Nessa perspectiva, o não padronizado era indesejado e excluído da aula. A brincadeira e o prazer apareceram fortemente como moeda de troca também nas práticas punitivas da professora. Interessante observar que em diversas situações, em decorrência de os alunos não apresentarem o comportamento desejado, a professora os privava da realização das aulas na quadra, como punição.

Observamos que, nas reuniões do corpo pedagógico, ocupava lugar privilegiado, a discussão sobre a punição a ser aplicada, aos alunos, em caso de transgressões às normas disciplinares. Observamos, nos relatos de professoras e da coordenação, a manifestação de forte interesse em aplicar sanções como a suspensão e expulsão dos alunos que transgredem as normas, acrescido de um inconformismo por não poderem aplicar tais sanções.

Nesse caso, a coordenação, questionava sobre a possibilidade de se fazer um trabalho como punição com os alunos que "ganham ocorrência" repetidas vezes durante o ano. A insistência é explicitada em questionamentos como: "Então, até doze anos, a criança não pode varrer um pátio?". "E a suspensão"? E ainda, uma professora regente observa: "Um grande número de alunos traz confusão, traz empurra, empurra, 'passação' de mão, a gente deve aceitar tudo?”. O encaminhamento da direção, em relação aos apelos se dava de forma mais moderada, de acordo com a lei: "Não como punição, não como castigo, mas como projeto pedagógico". Tal atitude fazia crescer ainda mais inconformismo por parte dos coordenadores. 
Interessante é observar como as infrações às regras disciplinares são postas como delitos. Segundo Foucault (2007), o mecanismo disciplinar comporta em sua essência um pequeno mecanismo penal, que se constitui como peça indispensável à eficácia do sistema disciplinar, uma vez que submete o indivíduo a uma rede de coerção permanente com o intuito de normalizá-lo. Esse sistema busca alcançar todo um conjunto de comportamentos que não passam pelo crivo da lei, mas que podem vir a perturbar o funcionamento do sistema disciplinar:

Na oficina, na escola, no exército funciona como repressora toda uma micropenalidade de tempo (atrasos, ausências, interrupções das tarefas), da atividade (desatenção, negligência, falta de zelo), da maneira de ser (grosseria, desobediência), dos discursos (tagarelice, insolência), do corpo (atitudes incorretas, gestos não conformes, sujeira), da sexualidade (imodéstia, indecência) [...]. Trata-se ao mesmo tempo de tornar penalizáveis as frações mais tênues da conduta, e de dar uma função punitiva aos elementos aparentemente indiferentes do aparelho disciplinar: levando ao extremo, que tudo possa servir para punir a mínima coisa; que cada indivíduo se encontre preso numa universalidade punível-punidora (FOUCAULT, 2007, p. 149).

Já em relação às condutas que sinalizam um exercício da liberdade, essas apareceram, em maior parte, de forma mais incipiente. As condutas do primeiro ano evidenciaram o humor, o riso, os movimentos não padronizados, como escapatória à disciplinarização. A partir dessas atitudes sorrateiras e fugidias do olhar vigilante da professora, vimos como as relações de poder podem ser flexíveis e reversíveis, pois os alunos exerciam o poder na direção de seu fazer livre. As burlas dos alunos revelaram a ineficácia da pretensão de controle das condutas. Vistas como indisciplina, na verdade, essas burlas afirmam esses corpos como sujeitos e, como tais, têm "[...] diante de si um campo de possibilidades onde diversas condutas, diversas reações, diversos modos de comportamento podem acontecer" (FOUCAULT, 1995, p. 244). Ou seja, diante daquilo que Ihes é apresentado pela via do poder, o humor, o riso, estrelinhas e cambalhotas são possibilidades criadas. 
A conduta da professora Clarice com sua turma acentuou um tipo de relação na qual a condução dos alunos se fazia pelo prazer, pela música, pelo movimento rítmico, e, também, pelo envolvimento dos alunos nas tomadas de decisão, assim como o aproveitamento dos saberes trazidos pela turma, com a consequente ampliação dos saberes. A metodologia funcionava como um convite à construção da liberdade junto aos alunos.

Por fim, a atitude crítica na voz da professora Mercedes, em reunião com o corpo pedagógico, revelou o questionamento das condições da escola. Nesse diagnóstico, era latente o vislumbrar de outras possibilidades de ação. A professora denunciou a precariedade das condições de trabalho com salas superlotadas, a pressão dos órgãos de avaliação institucional como o Ideb[10], sem deixar de incitar o corpo pedagógico à luta. Conforme Mercedes,

Nós estamos trabalhando dentro da lei, nós temos que aceitar as leis, mas as leis vêm justamente para normatizar e nos fazer aceitar as coisas. Se nós continuarmos com essa concepção, nós não vamos mudar nada. Precisamos pensar grande. O movimento de greve, que é um movimento que poucos participaram e ainda levamos nome de preguiçosos, que não queremos trabalhar, as salas cheias e o ldeb vem nos cobrar qualidade de ensino. São proporcionadas condições? Nós estamos trabalhando doentes. Eu estou doente. O bairro 'Sol Nascente' é diferenciado, nós precisamos de um trabalho diferenciado.

A atitude crítica, para Foucault (1978), remete ao ato de questionar, diante de uma dada forma de governo, os efeitos de poder a partir dos quais os indivíduos seriam conduzidos. A atitude crítica se manifestou no franco falar da professora com o questionamento em face à autoridade da lei, dos órgãos de avaliação da qualidade da educação.

A professora Mercedes vive esse contexto, mas almeja uma saída diferente, seja quando coloca um sistema de leis em questionamento, seja quando chama os professores à participação no movimento de greve, seja quando denuncia a 
especificidade da situação da escola. A atitude crítica da professora está relacionada com essa atualidade vivida da qual faz parte e a partir da qual vislumbra a construção de possibilidades. Podemos nos questionar até que ponto os sujeitos são disciplinados nas próprias condutas? Até que ponto, as condutas do próprio corpo pedagógico não foram normalizadas pelo sistema disciplinar?

É nesse sentido que a preocupação com as condições de existência na escola, aberta nessa fala, aproxima-se da discussão da atualidade em Foucault (2010), para quem a tarefa da filosofia é traçar uma "ontologia crítica do presente", ou seja, traçar um diagnóstico do presente, no qual seria preciso nos defrontar com a questão sobre o que é a atualidade como momento em que vivemos, no qual agimos e nos situamos. Esse diagnóstico da atualidade abarca, ao mesmo tempo, uma ontologia crítica do presente e de nós mesmos como sujeitos de ação neste presente.

\section{CONSIDERAÇÕES FINAIS}

Os dados nos mostraram a complexidade e a heterogeneidade do espaço escolar em que diversas condutas convivem. Nesse sentido, há disputas com objetivos diferentes: enquanto há pretensão de controle dos corpos conforme a disciplinarização, outros buscam conduzir-se de modo a vivenciar as experiências de diversas formas e não apenas sob o modo da disciplinarização, da rigidez. E ainda, há a busca de uma forma mais livre na condução dos sujeitos, que tem proximidade com o pensamento de Foucault quando afirma que não há problema em um professor que sabe mais conduzir a turma de seu modo, uma vez que, não se exceda no uso do poder.

Além de haver conflitos entre as diversas condutas, convivem simultaneamente, ações disparatadas, pessimismo, esperança, dominação, germens de liberdade. Isso nos leva a refletir sobre o que é essa escola na qual algumas condutas são afirmadas enquanto outras são negligenciadas. Instiga-nos, assim, a refletir sobre as implicações dessas formas de conduta para a experiência educativa nesse espaço. Quais as implicações dessas ações em um espaço que se coloca como lugar de ampliação e construção de conhecimento? Na busca de respostas a essas questões, é preciso um olhar mais atento para os corpos como superfícies marcadas pela história, como 
materialidades que se comunicam imediatamente com o outro. Estar atento ao que os alunos trazem ao espaço escolar é uma possibilidade de ampliar as experiências do conhecer na escola.

É preciso repensar os controles do corpo e dos prazeres e a sua relação com o processo educativo que se almeja nesse espaço. A assepsia das condutas é redutora das experiências dos alunos. Os dados mostraram, nesse sentido, um enrijecimento quase estéril e ineficaz quanto a seus próprios objetivos. É preciso pensar até que ponto esse controle é uma necessidade ou é uma prática que a escola reproduz em sua rotina sem maiores reflexões. $E$, até que ponto as pessoas responsáveis pela organização do espaço escolar não foram disciplinadas e controladas por suas próprias condutas?

Como nos aponta o próprio Foucault (2006), nos países industrializados, as disciplinas entraram em crise na sociedade, o que possivelmente se relaciona às transformações socioculturais da segunda metade do século XX. Apontamos, nesse sentido, a ineficácia da escola como instituição disciplinar, haja vista a ineficiência de seus mecanismos como forma de conduzir as condutas. Nesse ínterim, há de se ressaltar que o projeto que corroborava o uso das disciplinas na escola moderna, era o de formar operários para o trabalho na sociedade capitalista industrial. Tal constatação nos faz refletir sobre o espaço escolar como projeto de formação humana, ou melhor, que tipo de relações de poder a escola almeja produzir?

Observamos também que as salas cheias, os horários marcados e, no caso da Educação Física, os escassos 50 minutos conduzem, algumas vezes, a esse tipo de conduta que faz passar a regra por cima do viver, da experiência plena. O desafio é pensar em não disciplinar as condutas a ponto de colocar regras de organização como princípios máximos de condução, uma vez que essa forma de conduta exila outras, criativas e renovadoras. É também valorizar experiências, sinuosas, deslizantes e errantes, no outro e em si mesmo. Mas como fazê-lo, se a rotina, a rigidez nos constitui e enrijece? 
Foucault (1979) incita a pensar o corpo como superfície de inscrição de acontecimentos e, por isso mesmo, pode ser campo da descoberta e da liberdade. É preciso potencializar essas forças, não apenas o corpo da biomecânica, dos movimentos padronizados, mas o corpo que dança e se move com intenção, desejo, vontade. A escola poderia dar um salto qualitativo, não como máquina de ensino, mas como espaço de experiências sensíveis tão necessárias a qualquer ser humano.

Pensar cada espaço da escola e o espaço-escola como lócus de experiências sensíveis é um desafio e soa como uma provocação. Nesse sentido, era perceptível, na EMEF, como trabalhos com a dança, o teatro e a música, que são tidos como conhecimentos menores, potencializaram a participação ativa dos alunos e minimizaram as resistências. Condutas como as da professora Clarice são tão profícuas em conduzir os alunos, quando comparadas com condutas coercitivas, que nos fazem refletir sobre como ampliar as experiências no espaço escolar. Interessante é que, mesmo sendo uma professora "regente de classe", incumbida do ensino de disciplinas como Matemática, História, Português, Ciências e Geografia, percebemos na conduta da professora Clarice, uma forma de lidar com os corpos sem imprimi-los de rigidez. Os olhares ali eram vivos, atentos. O corpo-movimento fazia-se presente. A conduta da professora impactava, direcionando os alunos ao exercício da liberdade. É preciso, conforme Foucault sugere, nos afirmar como força criativa.

Se o próprio corpo pedagógico da escola está inserido em um tipo de racionalidade que o conduz a formas de intervenção via controle disciplinar, pelo lado dos alunos, há uma recusa que se torna, na verdade, um empecilho à captura total deles por essa lógica. Diante de comportamentos "não ideais", a escola parece buscar uma afirmação maior da punição e da disciplina. No entanto, é preciso identificá-los, pois, de outro lado, vários comportamentos "não ideais" podem não representar, de fato, uma ameaça a ao convívio respeitoso entre os diversos sujeitos. Há uma naturalização dessa saída generalizante sem considerar em que medida algumas condutas dos alunos podem prejudicar ou potencializar a vida. O problema é que, à proporção que essa saída é afirmada, repetidas vezes, e de modo arbitrário, ela perde sua 
credibilidade e mostra a sua face de ineficácia dentro dos objetivos para os quais ela existiria.

A intensidade com a qual foram realizadas essas burlas nos leva a questões sobre a produção das subjetividades no espaço escolar: que tipo de sensibilidade a escola tem evocado a partir dessas condutas? Da renúncia de si e do outro como sujeito? Da condução pela via da obediência? Para qual estética isso aponta? Pensamos que o desafio na escola é conduzir os alunos para a transmissão, construção e ampliação de conhecimentos, com o mínimo de coerção. Em resposta à afirmação do domínio nas relações em diversos momentos na escola, a instituição de um governo de si pelos sujeitos colocou-se como obstáculo ao controle total de suas condutas.

Limitar os excessos nas relações de poder, para construir outros tipos de relação, torna-se fundamental para a ampliação das experiências educativas no espaço escolar. É nesse espaço e tempo que se tornam necessárias atitudes críticas que conduzam ao exercício da liberdade.

Essa atitude crítica apontaria a necessidade de desnaturalizar algumas condutas. Desnaturalização como reflexão do que somos para recusar aquilo que somos e, assim, vislumbrar ações possíveis. Na relação de poder como conduta, situa-se, segundo Foucault (1995), a teimosia da liberdade, provocando, obstaculizando a pretensão de captura total dos corpos dos indivíduos. A teimosia da liberdade se expressa nas burlas dos alunos, nas escolhas das formas de serem conduzidos e nas recusas de um controle total de seus corpos. Mais ainda, a liberdade é feita na discussão, na problematização do presente, e, a partir dessa problematização é que se podem vislumbrar possibilidades com um olhar para dentro do espaço escolar, por aqueles que o compartilham.

Foucault (2010) afirma como tarefa da filosofia a realização de um diagnóstico da atualidade. E o que tentamos aqui, mesmo parcialmente, senão um inventáriodiagnóstico das condutas no espaço escolar? Inventário de condutas que se inserem nesse tempo presente, da vida presente, de sujeitos que compõem com sua vida essa atualidade na EMEF "Ordem e Progresso". 
Esse diagnóstico, a partir da concepção de Foucault, vislumbraria possibilidades de ação. Não como quem observa de fora, mas como um espelho no qual podemos nos ver e perguntar quem somos nós, o que fazemos no tempo presente e, o principal, o que podemos fazer. É a partir desse diagnóstico que podemos almejar saídas diferentes. Saídas diferentes da disciplinarização de alunos e professores, para compor uma escola que potencialize e dê vazão à vida. Saídas diferentes da dessensibilização naturalizada na escola e nessa sociedade que não reconhece no outro o si mesmo. Saída diferente da conduta que impele os indivíduos a adotarem e internalizarem a coerção, juntamente da vigilância e da punição, como modos próprios e únicos de se conduzir ou governar as relações nos espaços escolares.

Portanto, esperamos que, a partir da breve apresentação desse inventário das condutas no espaço escolar, tenhamos mostrado a complexidade de relações de poder produzidas e reproduzidas em seu interior. Como desdobramento dessa análise, trouxemos questionamentos sobre a atualização de nosso modelo escolar, modelo que comporta resquícios de um poder disciplinar, que se apresenta ineficaz na produção de condutas desejadas, mas que, nas burlas a esse sistema, mostra uma alternativa possível. Assim, torna-se emergente a necessidade de a escola discutir seus modelos organizacionais com base na sua própria atualidade e experiências de alunos, professores e demais sujeitos componentes desse espaço.

\section{REFERÊNCIAS}

ANDRÉ, Marli Eliza Dalmazo Afonso de. Etnografia da prática escolar. 17. ed. Campinas: Papirus, 2010.

FOUCAULT, Michel. A ética do cuidado de si como prática da liberdade. In:

Ditos e escritos: ética, sexualidade, política. Rio de Janeiro: Forense Universitária, 2004.

A sociedade disciplinar em crise. In: Ditos e Escritos: estratégia, poder-saber. Rio de janeiro: Forense Universitária, 2006. v. IV 
. A hermenêutica do sujeito. 2. ed. São Paulo: Martins Fontes, 2006.

. Ditos e escritos: ética, sexualidade e política. Paris: Gallimard, 2004.

História da sexualidade I: a vontade de saber. Lisboa: Relógio d’Água, 1994.

. Microfísica do poder. Rio de Janeiro: Graal, 1979.

. O governo de si e dos outros: curso no Collège de France (1982-1983). São Paulo: Martins Fontes, 2010.

. O que é crítica? Tradução de Gabriela Lafetá Borges. In: Conferência proferida em 27 de maio de 1978. Disponível em: <www.unb.br/fe/tef/filoesco/foucault/critique.html>. Acesso em: 12 maio 2012.

O sujeito e o poder. In: DREYFUS, Hubert Leiderer; HABINOW, Paul. Michel Foucault: uma trajetória filosófica. Rio de Janeiro: Forense Universitária, 1995.

Vigiar e punir: nascimento da prisão. 34. ed. Petrópolis: Vozes, 2007.

ORTEGA, Francisco. Amizade e estética da existência em Foucault. Rio de Janeiro: Graal, 1999.

SENNELART, Michel. Situação dos cursos. In: FOUCAULT, Michel. Segurança, território e população. São Paulo: Martins Fontes, 2008. p. 495-538.

VALONES, Neide Maria Alves. O poder disciplinar no cotidiano escolar. 2003. Dissertação (Mestrado em Educação) - Programa de Pós-Graduação, Universidade Federal de Pernambuco, Recife, 2003.

VARELA, Julia.; ALVAREZ-URIA, Fernando. A maquinaria escolar. Teoria \& Educação. Porto Alegre, n. 6, p. 225-246, 1992.

VEIGA-NETO, Alfredo; SARAIVA, Karla. Educar como arte de governar. Currículo sem Fronteiras, v.11, n.1, pp.5-13, Jan/Jun 2011. 


\section{APÊNDICE - REFERÊNCIAS DE NOTA DE RODAPÉ}

3. Conferir Valones (2003), Varela; Avarez e Uria (1992).

4. Os estudos de Foucault (2007) sobre o sistema punitivo em instituições, como a prisão, o hospital, a caserna e a escola, trouxeram à tona o poder disciplinar como mecanismo que operava no nível do detalhe do movimento dos corpos, não para excluí-los ou supliciá-los, mas para gerir suas ações e potencializá-las ao máximo, conferindo a esses corpos as condições de docilidade e utilidade.

5. Sobre o poder disciplinar, ver Foucault (2007).

6. Essa interpretação do poder desenvolvida por Foucault (1994), inspirada em Nietzsche, concebe a relação poder e resistência na ordem da guerra e do enfrentamento.

7. A arte de governar tratada como governamentalidade se refere à racionalidade política que põe em exercício um governo da população, a partir dos mecanismos de segurança, e formas de governar individualizantes dentro das instituições.

8. O cuidado de si "[...] designa algumas ações, ações que são exercidas de si para consigo, ações pelas quais nos assumimos, nos modificamos, nos purificamos, nos transformamos e nos configuramos. Daí uma série de práticas que são, na sua maioria, exercícios [...]" (FOUCAULT, 2006, p.14-15).

9. Para preservar o seu anonimato, o nome da escola, do bairro em que se situa a mesma e dos sujeitos participantes da pesquisa são fictícios. A sigla EMEF significa "Escola Municipal de Ensino Fundamental", nomenclatura adotada por todas as escolas do município.

10. Índice de desenvolvimento da educação básica.

Enviado: Abril, 2020.

Aprovado: Maio, 2020. 